\title{
The Indonesian version of irrational beliefs tests in rational emotive behavior therapy: adaptation of irrational beliefs tests
}

\author{
Maria Margaretha ${ }^{*} 1$ \& Sri Hastuti ${ }^{2}$ \\ ${ }^{12}$ Universitas Sanata Dharma \\ *)Corresponding author, ఏe-mail: rethahd@gmail.com
}

\begin{abstract}
This Indonesian version of Irrational Beliefs Test (IV-IBT) measures the irrational thoughts in accordance with the irrational belief's concept by Albert Ellis (Rational Emotive Behavior Therapy) and is the result from the language and cultural adaptation of Irrational Beliefs Test (IBT; Richard Garner Jones, 1968). There are 10 irrational thoughts contained in IBT namely demand for approval, high self-expectation, blame proneness, frustration reactive, anxious overcome, problem avoidance, dependency, helplessness, perfectionism. IBT consists of 100 items originating from 10 items for each type of irrational thoughts. The IBT adaptation process was conducted using the Guidelines for test translations (van de Vijver \& Hambleton, 1996), and further elaborated into four major steps, namely (1) the translation from English into Indonesian by an expert in English language and a psychologist, and from Indonesian into English by two experts in English language, (2) content validity assessment by three assessors who master the REBT concepts and psychological measurement, (3) dimensionality examination with exploratory factor analysis, (4) empirical testing to obtain the accurate, adequate, and relevant item formulation involving 302 students. The Irrational Beliefs Test consists of 31 items, 10 factors, and is unidimensional (single dimension) in nature. Results and discussion are described in the Indonesian culture context.
\end{abstract}

Keywords:Adaptasi Tes, Irrational Beliefs, Irrational Beliefs Test (IBT), Rational Emotive Behavior Therapy

How to Cite:Margaretha, M.,\& Hastuti, S. (2017). The Indonesian version of irrational beliefs test in rational emotive behavior therapy: adaptation of irrational beliefs test. Couns-Edu: International Journal of Counseling and Education, 2(2): pp. 70-77. DOI: https://doi.org/10.23916/002017026220

This is an open access article distributed under the Creative CommonsAttribution License, which permits unrestricted use, distribution, and reproduction in any medium, provided the original work is properly cited. (C2017 by author and Indonesian Counselor Association (IKI).

\section{Introduction}

Conducting counseling based on theories and approaches appropriate with counselee's condition are one competence of a professional counselor who is related to guidance and counseling theoretical and practical frameworks. Further, choosing and administering instrument to reveal the actual condition of counselee is one competence of a professional counselor that is related to conceptual and practical mastery of assessment to understand condition, needs and problems of counselee. Those professional competencies are described in the Regulation of Minister of National Education No 27 in 2008 about Counselor Academic Qualification and Competence Standards.

Rational Emotive Behavior Therapy (REBT) is developed by Albert Ellis which start edits long journey since Rational Therapy (1955), Rational Emotive Therapy (1960s), and Rational Emotive Behavior Therapy (1990s) is one of the counseling theories orienting on cognition (Seligman \& Reichenberg, 2010; 
Winkel \& Sri Hastuti, 2012, Corey, 2013). Ellis proposes that basically human has strong tendency to live rationally, as well as irrationally. Therefore, human can think both rationally and irrationally. Their rational beliefs were introduced during early childhood in cultural of environment, and they tend to be implanted deeper since man strengthens them with various kinds of excuses. Therefore, irrational beliefs become the source of one's life problems (Winkel \& Sri Hastuti, 2012). A man is not disturbed by the event that had happened but by his view of the incident. So, the man disturbs himself with his rigid and extreme thoughts of the event (Corey, 2013). In the process of counseling, counselee's irrational beliefs can be transformed intorational ones through the process of disputing.

In line with Ellis' opinion that irrationall beliefs are sources of life problems, there are many irrational belief's scales based on Ellis' model. Bridgesetal. (2010) summarize the irrational beliefs into Irrational Belief Scale (Malouff \& Schutte, 1986), Camatta \& Nagoshi Scale (Cammata \&Nagoshi, 1995), Child and Adolescent Scale of Irrationality (Bernard \& Laws, 1987), Common Beliefs Survey-III (Bessai, 1977), Ellis Emotional Efficiency Inventory (Ellis, 1992), Evaluative Beliefs Scale(Chadwick, Trower, \& Dagnan, 1999), General Attitude and Belief Scale (Di Giuseppe, Leaf, Exner, \& Robin, 1988), Idea Inventory (Kassinove, Crisci, \& Tiegerman, 1977), Irrational Beliefs Inventory (Koopmans, Sanderman, Timmerman \& Emmelkamp, 1994), Irrational Beliefs Survey (Wason,Vassar, Plemel, Herder, Manifold, \& Anderson,1990),IrrationalBeliefsTest(Jones, 1968),Perfectionism Cognition Inventory (Flett, Hewitt, Blankstein \& Gray, 1998), Rational Behavior Inventory (Shorkey \& Whiteman, 1977), Situational SelfStatement and Affective State Inventory (Harrell, Chambless, \& Calhoun,1981), SmithIrrationalBeliefs Inventory (Smith, 2002), and Survey of Personal Beliefs (Demaria, Kassinove,\&Dill,1989).

From the afore mentioned Irrational Beliefs Scales, according to Bridgesetal. (2010), Irrational Belief Test (Jones, 1968), Rational Behavior Inventory (Shorkey \& Whiteman,1977), and Idea Inventory (Kassinove, Crisci, \& Tiegerman,1977)are the most frequently used and seen in many literatures. Irrational Beliefs Test (Jones,1968), specifically, are used for many studies because of its popularity and convenience. Some studies used IBT as their search instrument, among others are the influence of foreigners' irrational beliefs in second language towards class anxiety among students in Russia (Tittle, 1997), the relationship of IBT and students' anxiety and academic system in Iran (Khaledian, 2013), and the relationship of social anxiety, irrational beliefs, and emotional intelligence of students in Tehran (Kamae \& Weisani, 2014).

Based on the author's observation, there are many studies on the effective ness of REBT in Indonesia. Some of the studies are on students to reduce cheating habit (Hartanto, 2009), on clients with violence behavior and hallucination (Sudiatmika, 2011), on drug abusers to reduce anxiety about the future (Siburian, Karyono, Kaloeti, 2010), on the improvement of cognitive and social responses on violence victimclients (Putri, Keliat, best Nasution, 2012), and on students to help them to improve their emotional intelligence (Tyas, 2012). From the studies, the author finds many similarities,i.e.(1) there searchers do not report the inventory or irrational beliefs test administered to the subjects to detect their irrational beliefs,(2) the researchers do not report the dispute process to change irrational torational beliefs, and(3) techniques of REBT that a rerelated to changes on Effect and Behavior.

From 2007 to 2016, the author participates as an instructor for Education and Educational Training for Teacher (PLPG) for Guidance and Conseling teachers from several districts in Central Java. In counseling services, as manifested by the teachers, participants of PLPG, they conducted an assessment in counseling with only an interview (in take inter view), and even without the use of counseling theories and counseling approaches adequately. Further, for teachers who used REBT in their counseling, they never equipt it with the administration of a test or inventory of irrational beliefs in order to obtain more complete information and be more specific about the irrational beliefs owned by counselees. As it is known, the assessment in counseling services aims at getting information about the counselee with systematic ways such as through interviews (in take interview), test and inventory, behavioral observation, and variety of other relevant in formation.

Therefore, according to the author, test or inventory of irrational beliefs that are appropriate for counselee in Indonesian culture needs to be developed. Such development can be done by adaptation. The author adapts the language and culture of Irrational Beliefs Test (Jones, 1968) into Bahasa Indonesia. This Irrational Beliefs Test (IBT) use themodel of Ellis (Jones, 1968; Bridgesetal., 2010).The adaptation 
produces a test that is appropriate to the Indonesian context and given the name of The Indonesian Version Irrational Beliefs Test (IV-IBT). The Indonesian Version of Irrational Beliefs Test (IV-IBT) is expected to be used both as an assessment tool in counseling, especially REBT, as well as for research purposes.

\section{Basic Concept of REBT}

Rational-Emotive Behavior Therapy (REBT) is cognitive-oriented counseling approach that emphasizes the linkages between feelings, behavior and beliefs. The Rational-Emotive Behavior Therapy (REBT) approach is developed by Albert Ellis views human beings as individuals who have atendency to think irrationally. In addition, individuals also have the capacity tore-learn to think rationally (Seligman \& Reichenberg, 2010; Winkel \& Sri Hastuti, 2012). The main concept of REBT is that almost all emotions and behaviors are the results of beliefs, what is assumed or believed about one self, others, and the world at large. So, what humans believe about their situation-not the situation it self-determines how they feel and behave (Froggatt, 2005).

\section{Rational and Irrational Beliefs According to Albert Ellis}

According to Ellis, the individual has three levels of belief's, i.e. to think about what happened based opon the fact send the evidence, conduct an assessment of the facts and evidences, and confidence in the process of evidence and evaluation (Froggatt, 2005).

Ellis found that the source of emotional issues is irrational belief that can be categorized intofour,namely:(1)Demands, the demands or expectations that are not realistic and absolute to events or individuals who canbe identified by words like must, should and better;(2)Awfulizing isa way of exaggerating the negative consequences of a situation to the extreme level so that the unfavorable incidence becomes a very painful incident; (3) Low Frustration Tolerance (LFT)isacontinuation of the demands of always being in a comfortable condition and reflects intolerance againstd is comfort; (4) Global Evaluationsofhumanworth,whichisassessing theworth ofoneself and others. Thismeansthat individuals can beranked, which implies on assumption that some people are worst or unworthy of another (Seligman \& Reichenberg, 2010; Wallen, 1992). Ellis formulates 12 irrational ideas or beliefs as follows:

1. The idea that it is a dire necessity for an adult human being to beloved and approved by virtually every significant other person in his community (Demand for approval).

2. The idea that one should be thoroughly competent, adequate, and achieving in all possible respects if one is to consider one self-worth while (High self-expectation).

3. The idea that certain people are bad, wicked, or villainous, and that they should be severely blamed and punished for their villainy (Blame proneness).

4. The idea that it is awful and catastrophic when things are not the way one would very much like them to be (Frustration reactive).

5. The idea that human un happiness is externally caused and that people have little or no ability to control their sorrows and disturbances (Emotionalir responsibility).

6. The idea that if something is or maybe dangerous or fear someone should be terribly-concerned about it and should keep dwelling on the possibility of its occurring (Anxious over concern).

7. The idea that it is easier to avoid than to face certain life difficulties and self-responsibilities (Problem avoidance).

8. The idea that one should be dependent on others and needs someone stronger than one self on whom to rely (Dependency).

9. The idea that one's past history is an all important determiner of one's present behavior and that because something once strongly affected one's life, it should in definitely have similar effect (Helplessness).

10. The idea that there is invariably a right, precise, and perfect solution to human problems and that it is catastrophic if this perfect solution is not found (Perfectionism).

Irrational beliefs, characterized by an absolute extreme, logically incorrect (wrong), not consistent with reality, and hindering individuals from objectives (Maultsby,1984 in Seligman \& Reichenberg, 2010), is a continuum from the specific to the abstract (Di Giuseppe, 1991, in Neenan \& Dryden,1999). 


\section{ABCDEFModelinREBT}

In the implementation of case handling, REBT adheres to the order of the identification, assessment, disputing, and modifications of irrational beliefs in ABCDEF model (Ellis,1995 in Seligman \& Reichenberg, 2010: 258). ABCDEF stands for Activating Event (A), Belief (B), Consequences (C), Dispute (D), Effect (E), F (new feeling).

Activating Event (A) is a particular incident or experience that is perceived by the subject in the form of an interpretation of $\mathrm{A}$ and form a belief (B) which can be rational or irrational. Emotional reaction and behavior (Consequences) are the result of a rational mind which can be a reason able feeling. However, un reason able feeling and adaptive or non-adaptive behaviors can occur as a result of irrational beliefs. Dispute is the application of methods to help counselee to challenge irrational beliefs. Dispute consists of three components, namely detecting (invention), debating (debate), and discriminating (distinction between irrational with rational beliefs). Dispute is to lead to effect (Effects). Effect is a new philosophy that includes practical aspects and belief system changes: from irrational becomes rational. F (new feeling) describes feelings and behaviors that are new as a result of effective rational beliefs (Corey, 2013; Seligman \& Reichenberg, 2010; Winkel \& Sri Hastuti, 2012).

\section{Irrational Beliefs Test (IBT)}

Jones (1968) develops a test, Irrational Beliefs Test (IBT), which is valid and reliable based on Ellis' concept to measure the extent of a person's irrational beliefs. IBT consists often separated scales that measure the specific irrational thinking in it seach scale.There are ten items in each scale so that the total numberis 100 items. The following are examples of items within each scale:

1. "it is important to me that others approve of me"(demands for approval)

2. "I hate to fail at anything" (High self-expectation)

3. "Peoplewhodowrongdeservewhat they get"(Blame proneness)

4. "Frustration do not upset me"(Frustration reactive).

5. "I cause my own moods" (Emotional irresponsibility).

6. "I have a fear of something's that often bother me"(Anxious over concern).

7. I avoid facing my problems" (Problem avoidance).

8. "Every one needs someone they can depend on for help and advice"(Dependency).

9. "It is almost impossible to over come the influence over the past"(Helplessness).

10. "There is a right way to do everything"(Perfectionism).

This scale is in Likert scale with five responses for each item,i.e. strongly disagree, moderately disagree, neither agree or disagree, moderately agree, and strongly agree. IBT provides both individual scale and total scores.

\section{Method}

This test adaptation follows the Guide lines for test translations (van de Vijver \& Hambleton, 1996) and is conducted information stages, which will be described below.

1. Translation process. This translation process aims to produce formulation of items appropriate to the context or culture of Indonesia. This process follows the stages as follows: (1) two translators (an English expert and a psychologist) separately translated IBT into Indonesia version, (2) both translations were assessed in terms of the equivalence by a panel of a psychologist and an expert of counseling who master English well, (3) IBT in Bahasa Indonesia version was then retranslated separately by two English linguistics experts,(4) the back translation results were compared with the original IBT by a panel, (5) conducting pilot study which involved 15 respondents to find out what problems emerging when the respondents worked on the IBT in Bahasa Indonesia

2. Content validity assessment. Three raters who understand the concept of REBT and psychological scales were involved to assess the relevancy of each item with the observed constructs. The assessment was measured with Content-Item Validity Index (IVI-I) minimum= 0.78 (Lynn, 1986, in Supratiknya, 2016) and Content-Scale Validity Index (IVI-S/R) minimum $=0.90$ (Polit \& Beck, 2006 in Supratiknya, 2016). For IVI-I less than 0.78 , the items were revised. 
3. Scale measurement dimensionality with exploratory factor analysis. The Psychology measurement dimensionality is the measurement's factor structure, i.e. the total and visibility of variables revealed in the items. This scale data dimensionality involved 302 students ranging between 18-24 years old. In detail, the steps of exploratoric factor analysis were as follows (Supratiknya, 2016): (1) determining the data feasibility to be the subject of factor analysis by means of sample size and Kaiser-Meyer-Olkin (KMO) sample feasibility or Bartlett sphericity test with index of $\geq 0.50$ and significances of $p<0,05$.In the anti-image, the correlation was $\geq 0.50$, (2) conducting factor extraction by using Principal Axis Factoring (PAF) to identify or to find a variety of latent constructs under lying the measured variables.

4. Empirical test to get items that are appropriate, adequate, and relevant. This empirical test was still included in exploratoric stages to (1) determine the number of factors using Kaiser and Scree test criteria with "eigenvalue $>1$ ",(2) conduct factor rotation to maximize high item loading as well as low item loading, (3) conduct interpretation by determining which items that form a factor. Traditionally, a factor should be formed by at least twoor three items. The process of naming was subjective, theoretical, and inductive byre lying on the author's assessment result on commonth read of items content that form each factor (Williams, 2010 as cited in Supratiknya, 2016).

\section{Results and Discussions}

The result of IVI-I index was 0.66-1.00. Eight of 100 items have the index $=0.66$, mean while the rest was 1.00 . For items with index $=0,66$, they were revised. Mean while the measurement of IVI-S/R on this scale was $96,8: 100=0,96$. it means that the scale is good. The factor's extraction was done three times with the following results:

Table 1 Factors extraction result

\begin{tabular}{cllll}
\hline $\begin{array}{c}\text { Factor extraxtion, } \\
\text { thn }\end{array}$ & Item & KMO & Signdegree (p) & Correlation among items (anti image) \\
\hline $\mathbf{1}$ & 100 & 0.693 & 0.00 & 98 items ranin $0.50-0.75$ \\
$\mathbf{2}$ & 98 & 0.702 & 0.00 & 34 items ranging $0.50-0.80$ \\
$\mathbf{3}$ & 34 & 0718 & 0.00 & $0.52-0.82$ \\
\hline
\end{tabular}

The third factor extraction resulted in 11 factors. However, the eleventh factors have correlation value of -0.217 , so the factors should be deleted. The other ten factors correlated to one another with 32 items ranging from 0.06-0.320. This data showed that the scale's items are unidimensional. It means that the scale reveals the same single psychological dimension that is irrational beliefs.

In the item analysis measurement, among 34 items, there were two items with $\mathrm{r}$ it of $\leq 0.190$. Meanwhile the other items $r$ it was ranging from 0.192-0.363 ( $\mathrm{r}$ it $\geq 0.190$ as the margin). Thus, the end result of the factor analysis and item analysis were 31 items with 10 factors. The reliability test with Cronbach Alpha technique produced reliability coefficient of 0.701 . The ten factors were (1) excessive worry, (2) excessive selfconfidence, (3) dependency to others, (4) a sense of helplessness, (5) avoiding responsibility, (6) demand to be accepted, (7) demand to comply with norms, (8) idea of horrible life, (9) emotionally irresponsible, (10) inability to overcome problems.

Table 2 The indonesian version of irrational beliefs test (IV-IBT)

\begin{tabular}{cll}
\hline $\mathbf{N o}$ & \multicolumn{1}{c}{ Factor's name } & \multicolumn{1}{c}{ Irrational beliefs content and number of item } \\
\hline $\mathbf{1}$ & Excessive worry & High self-expectation (1), Anxious over concern (3), \\
& & Frustration reactive (1) \\
$\mathbf{2}$ & Excessive self- Confidence & $\begin{array}{l}\text { Frustration Reactive(1), Emotional Irresponsibility (1), } \\
\text { demand for approval (1), high self- expectation (1) }\end{array}$ \\
& & Depedency(3) \\
$\mathbf{3}$ & Dependency to others & Helplessness (2), Perfectionism (1) \\
$\mathbf{4}$ & A sense helplessness &
\end{tabular}




\begin{tabular}{cll}
\hline $\mathbf{5}$ & Avoiding responsibility & ProblemAvoidance(3), Blame Proneness (1) \\
$\mathbf{6}$ & Demand to be accepted & Demandof Approval (2) \\
$\mathbf{7}$ & Demand to comply with norms & BlameProneness(1), Perfectionism (1) \\
$\mathbf{8}$ & Idea of horrible life & High Self- Expectations(1),Blame Proneness (1), \\
& & Frustation Reactive(1), BlameProneness (1) \\
$\mathbf{9}$ & Emotionally irresponsible & Emotional Irresponsibility (2) \\
$\mathbf{1 0}$ & In ability to overcome problems & Helpessness (1), High Self-Expectations (1) \\
\hline
\end{tabular}

The adaption into Indonesian Version of Irrational Beliefs Test; IV-IBT was meant to obtain a relatively standard irrational beliefs scale which can be used as an assessment tool in REBT counseling, other than for the purpose of research in the field of counseling. As an assessment tool, The Indonesian Version of Irrational Beliefs Test (IV-IBT) could be used to identify irrational beliefs emerging and how strong the beliefs are. In the ABCDEF model, in general, a counselor helps the counselee to realize irrational thoughts (Beliefs) through interviews with various supportive counseling verbal techniques. To further ensuring what irrational beliefs emerging and how strong they are,the counselor cangive the counselee the Indonesian Version of Irrational Beliefs Test.(IV-IBT)The result is then used as acomplement to the out come of the interview. Thus, the process of disputing conducted by counselors is on target.

The factors resulting from The Indonesian Version Irrational Beliefs Test; IV-IBT as shown in Table 2 above are interesting tobe examined. Depending on others (Dependency), demand tobe accepted (Demand of approval) and being not dependent emotionally (emotional irresponsibility) are formed by items like the original version, as well as a sense of helplessness (helplessness) and avoiding responsibility (Problem avoidance) are also pre-dominantly shaped by items of helplessness and the Problem avoidance of the original version. It means that there are some items that clearly reflect the irrational beliefs of Indonesian people. However, among the three irrational beliefs, dependency is strongly visible.The items only form and appear in the dependency factor and no other dependency item's factor were absorbed in other factors. The followings are the three items from dependency factor: (1) "Everyone needs someone they can depend on for help and advice",(2)"It ry to consult an authority on important decisions.", and (3) "People need a source of strength outside themselves". It means that the irrational belief of Indonesian people is the ones supposed to depend on others and require others who are stronger than them self to rely on.

Although the items of demand of approval are absorbed also on other factors,but the demand of approval formed from the two items as the original version can be categorized as strong as well. Both items forming demand of approval are "It is important to me that others approve of me", and "I want everyone to like me". This illustrates that the Indonesian people have a tendencyto demand others unrealistically to accept or like themselves.If this does not happen then life will be seen as a disaster.

Similarly, items of emotional irresponsibility are also absorbed on other factors. However, emotional irresponsibility is formed from two items from the original version. Both items are "People are disturbed not by situations but by the view they take of them" and "I cause my own moods". Both items reflect that people got distracted by them self. Emotional irresponsibility is an idea that an individual does not have or lack of the ability to control problems that cause sadness and unhappy life. Because their unhappiness is caused by factors outside them self.

The helplessness factor is clearly visible on items: (1) "It is almost impossible to overcome the influence's of the past,"(2)"Just because something once strongly affects your life doesn't mean it needs to do so in the future", and (3) "There is seldom an easy way out of life's difficulties". It reflects that Indonesian people are more likely to focus on the circumstances in the unhappy events or difficult circumstances in the past as the source of helplessness now. The influence over the past is very strong in the formation of helplessness in the present so that people constantly feel worse. 
A voiding responsibility factor is very clear from these items: (1)"I usually put off importance decisions,"(2)"I try to go ahead and get irk some tasks behind me when they come up", and(3)"Too many evil persons escape the punishment they deserve". Avoiding responsibility for Indonesian people tends to materialize in terms of procrastination and ignoring tedious tasks.

While for the other factors, apart from the five factors already described above, are formed from various irrational beliefs items of the original version. It reflects the dynamic relationship and tends tobe strong on those items to form an irrational belief factor for Indonesian people.

\section{Conclusions}

From the 100 items of Indonesian version of IBT from 10 scales of irrational beliefs, there are 31 items (31\%) and10 factors as the adaptation of IBT which are named The Indonesian Version of Irrational Beliefs Test (IV-IBT). Fiveoutoftenfactors ofirrational beliefs in The Indonesian Version of Irrational Beliefs Test (IV-IBT) are strongly formed from items from IBT scale version,i.e. Dependency, Demand of approval, emotional irresponsibility, Helplessness, and Problem avoidance. Mean while, the other five factors are formed from dynamic relationship from items in various scales of the original version. The Indonesian Version of Irrational Beliefs Test (IV-IBT) is intended tobe a counseling assessment tool based on Rational Emotive Therapy Behavior approach to identify the appearance of irrational belief's of the counselee meticulously. From the accuracy of irrational beliefs tendency detection, the disputing process could be focused on the beliefs. Therefore, REBT counseling is expected tobe more effective.

\section{Acknowledgments}

This article is the research result of Competitive Grant Research that is funded by the Directorate of Research and Community Services, Ministry of Research, Technology and Higher Education in 2016. This research on Irrational Beliefs Test (IBT) adaptation into the Indonesian version of Irrational Beliefs Test involves various parties.Prof. A. Supratiknya, Ph.D. (lecturer at Sanata Dharma University, Yogyakarta) as a member of the research team, expert in drafting the psychological scale as well as the translator of Irrational Beliefs Test into Indonesian in the Irrational Beliefs Test adaptation process.

Y.B. Gunawan, MA (lecturer at Sanata Dharma University, Yogyakarta) English linguist who translated the Irrational Beliefs Test into Indonesian in the Irrational Beliefs Test adaptation process. Fidelis Chosa K, M. Hum (lecturer at Sanata Dharma University, Yogyakarta) expert in English language who translated the Irrational Beliefs Test into English in the back translation process.

Patricia Angelina Lasut, M.Hum (lecturer at Sanata Dharma University, Yogyakarta) expert in English language who translated the Irrational Beliefs Test into English in the back translation process, as well as the editor of the English language.

Dr. Hongki Julie, M.Si (lecturer at Sanata Dharma University, Yogyakarta), an expert in statistics as well as the consultant of factor analysis statistical technique.

Erni Kristi Cahyaningsih, S.Pd, an alumnus of Guidance and Counseling Study Program, Sanata Dharma University, Yogyakarta, and Clara Vania, L. Puji Noviani, F. Gesta Cahyaningtyas, students of Guidance and Counseling Study Program, Sanata Dharma University, Yogyakarta, as the field task force that was in command of collecting and processing the data.

\section{References}

Bridges, K,R \& Harnish,R.J. (2010). Role of irrational beliefs in depression and anxiety: A Review. Health, 2 (8), 862-877.

Corey,Gerald. (2013). Theory and practice of counseling and psychotherapy. Belmont: Broks/Cole.

Froggatt,Wayne. (2005). Abrief introduction to Rational Emotive Behaviour Therapy. from www.rational.org.nz/prof-docs/Intro

Hambleton,R.K.. (2001). The next generation of the ITC Test Translation and Adaptation Guideline. European Journal of Psychological Assessment,164-172. 
Hartanto,D. (2009). Penggunaan REBT untuk mereduksi perilaku menyontek pada siswa Sekolah Menengah, Article.

International Test Commission, International Commission Guide lines for Translating and Adaptation Test version (2010).

Jones,R. Gardner. (1968). A factor measured of Ellis' irrational belief system with personality and maladjustment correlate. Dissertation, Texas Technological College.

Kamae,A., \& Weisani, M.(2014). The relationship between social anxiety irrational beliefs and emotional intelligence with homesickness in dormitory students of Tehran University. Indian Journal of Fundamental and applied Science, 4 (1), 285-292.

Khaledian, M., Saghafi, F., Moradi, S., \& Khairkhah, Z. (2013). Investigating the Relationship of Irrational Beliefs with Anxiety and Their Effect in Two Different Academic Systems in Iran (Under graduate Collage students of Payam Nour University and Islamic Azad University). Journal of International Research Journal of Applied and Basic Sciences, 4(5), 1185-1191.

Lhor,J.M. \& Bonge,D. (1982). The factorial validity of their rational beliefs test:A psychometric investigation. Cognitive Therapy and Research, 6 (2), 225-230. 